\title{
Epigenetics Control Microglia Plasticity
}

\author{
Mathilde Cheray* and Bertrand Joseph \\ Toxicology Unit, Institute of Environmental Medicine, Karolinska Institutet, Solna, Sweden
}

Microglia, resident immune cells of the central nervous system, fulfill multiple functions in the brain throughout life. These microglial functions range from participation in innate and adaptive immune responses, involvement in the development of the brain and its homeostasis maintenance, to contribution to degenerative, traumatic, and proliferative diseases; and take place in the developing, the aging, the healthy, or the diseased brain. Thus, an impressive level of cellular plasticity, appears as a requirement for the pleiotropic biological functions of microglia. Epigenetic changes, including histone modifications or DNA methylation as well as microRNA expression, are important modifiers of gene expression, and have been involved in cell phenotype regulation and reprogramming and are therefore part of the mechanisms regulating cellular plasticity. Here, we review and discuss the epigenetic mechanisms, which are emerging as contributors to this microglial cellular plasticity and thereby can constitute interesting targets to modulate microglia associated brain diseases, including developmental diseases, neurodegenerative diseases as well as cancer.

Keywords: microglia, epigenetics, histone post-translational modification, DNA methylation, non-coding RNAs

\section{OPEN ACCESS INTRODUCTION}

Edited by:

Rocío Martínez De Pablos,

Universidad de Sevilla, Spain

Reviewed by:

Nabil Hajij,

Imperial College London, United Kingdom

Robert Adam Harris,

Karolinska Institutet (KI), Sweden

*Correspondence:

Mathilde Cheray

mathilde.cheray@ki.se

Received: 25 April 2018

Accepted: 18 July 2018

Published: 03 August 2018

Citation:

Cheray M and Joseph B (2018)

Epigenetics Control Microglia

Plasticity.

Front. Cell. Neurosci. 12:243.

doi: 10.3389/fncel.2018.00243
Microglia are the immune cells of the brain, they derived from myeloid precursors which migrate into the brain during early embryonic development and play a major role in maintaining a healthy environment in the brain (Ginhoux et al., 2010; Prinz and Mildner, 2011). Microglia are constantly screening the brain environment by using their surface receptors to detect damaged neurons, plaques, and infectious agents. In this steady or surveying state, microglia presents a high amount of ramified processes that perform constant screening of the central nervous system (CNS) environment. When activated by a stimulus, microglia can act as potent immune cells able to mediate innate and adaptive responses and to perform different function during CNS disease or injury. Microglia are of main importance for the brain homeostasis but uncontrolled or overactivated microglia can also contribute to brain diseases. Over-activated microglia can promote neuronal cell death in the course of neurodegenerative pathologies like Alzheimer's disease (AD), Parkinson's disease (PD), Huntington's disease (HD) as well as amyotrophic lateral sclerosis (ALS) (Sarlus and Heneka, 2017). Uncontrolled microglia will also lead to increase tumor cell migration and invasion in the case of brain tumor (Saijo and Glass, 2011).

Some of the main characteristics of microglia is their ability to adapt to their microenvironment and to acquire a specific phenotype based on stimuli they perceive. As innate immune cells they will become activated in response to injury, infection or death of cell in their vicinity (Eggen et al., 2013). Microglia can harbor different phenotypes depending of the signal they receive/detect from the microenvironment. Since microglia are frequently define as the macrophages of the brain, their classification and phenotypes have been established and named 
based on macrophages characteristics. Microglia will be activated in a pro-inflammatory phenotype or so called classical activation (M1 phenotype) in response to viral or bacterial infection, in the opposite, microglia will harbor an anti-inflammatory phenotype or alternative activation (M2 phenotype) in case of neurodegenerative diseases when detecting neuronal cell death for example. Worth a notice, the concept of the microglial M1/M2 polarization has been heavily questioned. In fact, it is now recognized that microglia display a continuum of activation states, which are largely oversimplified in the M1/M2 classification. However, since the M1/M2 paradigm has been heavily used in the literature, and for simplicity, references are made in this review to microglial M1 and M2 phenotypes. Recently, it has also been shown that microglia can acquire an alternative phenotype, or pro-tumoral phenotype, where the microglia cells are involved in increasing tumor invasiveness (Hambardzumyan et al., 2016). With the discovery of the ability of microglia to support tumor growth, it was shown that microglia is able to adapt to the microenvironment and its activation process and phenotype acquisition is more complex than thought. Indeed, microglia will harbor different transcriptional factor activation signatures depending on the phenotype they will acquire (e.g., neuroprotective, lipid response, neuropathic pain) which confirm the extreme plasticity of these cells and the complexity of the microglia phenotypical changes (Holtman et al., 2017). Thus, microglia fulfill multiple and contrasting functions across development and adulthood, in steady-state conditions, but also in the context of diseases. To perform their multiple functions, microglia appear to exhibit various phenotypes. Microglia thus appear to display extreme plasticity, and are able to modify their structure and functions based on their role and location. But, how can microglia obtain this level of cell plasticity?

In response to different stimuli, cells can change their state of activation and adapt their identity. These modifications are regulated by finely tuned modulation of gene expression. This coordinated regulation is mainly a result of changes in the composition and the structure of the chromatin, driven by epigenetic modulators. Recently, it has been shown that cellular and genomic reprogramming is highly dependent of chromatin modifications in order to lead and maintain the fidelity of target cell states. Epigenetic modifications such as histone modifications (e.g., methylation, acetylation, phosphorylation), DNA methylation or gene expression regulation by non-coding RNAs are crucial for normal development but can also be involved in diseases (Esteller, 2008). Epigenetic modifications do not modify the genome per se of the cell but they do regulate gene expression and thereby contribute to the definition of cell phenotype. For example, DNA methylation patterns, which are reversible heritable marks conserved during cell division, are involved in cell reprogramming processes (De Carvalho et al., 2010). Epigenetic modifications have been involved in cell phenotype regulation like the reprogramming of stem cells. Indeed, stem cells have the ability to self-renew or differentiate and these changes in cell phenotype involve a fine-tuned regulation by epigenetic mechanisms (Chung and Sidhu, 2008; Zhou et al., 2011; Katsushima and Kondo, 2014). Microglia can be compared to stem cells in their ability to adapt to the microenvironment and to differentiate into a specific cell phenotype in response to the signal activation. Thus, these cells are very plastic, however, until now, even if microglia have been known for almost a century, the mechanisms leading to their activation toward a specific phenotype are not yet fully established, but it seems obvious that epigenetic changes should contribute to the microglia plasticity.

Here, we review the roles of epigenetic alterations, including histone modifications, DNA methylation or microRNA expression, as well as the enzymatic systems regulating those modifications, may have in regulating microglia plasticity and polarization toward unique phenotypes. We also consider the contribution of the epigenetic control of microglia to their activation states in the context of health and disease, and possible long-term and lasting microglial effects such as the one observed upon microglial priming/memory or even transgenerational microglial effects.

\section{HISTONE MODIFICATIONS IN MICROGLIA}

The structure of the chromatin is regulated by its compaction depending on the organization of the histone proteins. The chromatin is composed of the DNA, tightly packed around histone proteins organized in units called nucleosomes. A nucleosome is composed by two $\mathrm{H} 3-\mathrm{H} 4$ dimers surrounded by two $\mathrm{H} 2 \mathrm{~A}-\mathrm{H} 2 \mathrm{~B}$ dimers corresponding to an octomeric core of histone proteins. Histone tails amino-terminal parts are protruding from the nucleosome, which make them accessible for possible post-translational modifications. Depending on the nucleosome spacing, the chromatin structure will be defined as heterochromatin and euchromatin. Heterochromatin corresponds to a condensed state of the chromatin while euchromatin is non-condensed or open chromatin. This open state of the chromatin allows the nuclear factors to access the chromatin. Modifications occurring on the histone tails and on the DNA are involved in the regulation of the chromatin structure and of the gene accessibility by the transcriptional machinery. Histones can be methylated, acetylated or phosphorylated on specific amino acids residues located on the histone tails. The chromatin accessibility is altered by histone acetylation which allow the interaction of DNA binding protein to accessible sites in order to activate gene transcription. Histone acetylation is carried out by histone acetyl transferases (HATs), which acetylate the lysine residues on histones tails or core, on the converse, the role of histone deacetylases (HDACs) is to remove the acetyl groups from those lysine residues. Histone methylation is either associated to transcription activation or repression depending on which amino acid the modification occurs. Histone methyltransferases (HMTs), promote the monodi- or tri-methylation on target histone residues, whereas histone demethylases (HDMs) counteract the effects of the HMTs.

The potential use of HDAC inhibitors in inflammatory/neurodegenerative diseases has been extensively 
investigated, since histone acetylation was shown to regulate the extent of inflammatory response (Blanchard et al., 2002; Ito et al., 2002). In the recent years, HDAC inhibitors have been widely used to target microglia with the aim of reducing inflammation. Valproic acid (VPA), defined as a non-selective HDAC inhibitor, is a FDA approved drug used to treat epilepsy and bipolar disorders. In the context of spinal cord injury, the ability of this drug to reduce the inflammatory response after injury and to avoid the appearance of exacerbating pathogenic events was assessed. In their study, Abdanipour et al. (2012) observed a reduction of the local inflammation and a reduction of microglia activation (as illustrated by reduction of the ED1 lysosomal marker), which was associated with an improvement in the animal, behavior, in rats treated with VPA after the injury. The use of VPA to target microglia has also been studied in the context of inflammation and innate antiviral gene expression (HIV for example) using a model of primary human microglia and astrocytes treated with TLR3 or TLR4 ligand. VPA has a direct effect on microglia since it suppresses the expression of chemokine and cytokine gene expression, of innate antiviral molecules (like IFN $\beta$ ) and of protein related to the activation of the TLR3-TLR4 signaling pathway (Suh et al., 2010).

The potential use of TSA to target microglia has also been widely explored. Its effect was tested on lipopolysaccharide (LPS)induced inflammatory response in microglia. TSA treatment has been described first as strongly potentiating the inflammatory response induced by LPS treatment in different models: from the N9 cell line and primary microglia cells to hippocampal slices culture as well as in neural co-cultures (Suuronen et al., 2003). More recently, TSA has been defined as a suppressor of the inflammatory phenotype of microglia after LPS treatment. Indeed, HDAC inhibition by TSA or SAHA (also known as Vorinostat) leads to a suppression of cytokine expression and release after LPS induction in primary microglia cultures (Kannan et al., 2013), but also in the mouse brain where cognitive dysfunction induced by LPS (weight loss, anorexia, and social withdrawal) was also attenuated (Hsing et al., 2015). Moreover, hyperacetylation induced by TSA treatment has a neuroprotective effect in the female neonatal mouse after LPS and hypoxia-ischemia and correlates with an improvement of long-term learning (Fleiss et al., 2012).

As VPA and TSA, sodium butyrate (SB) has also been studied for its potential role in inflammation regulation through microglia targeting. In this matter, it has been shown that SB induces changes in microglia shape, with apparition of microglial processes elongation in inflammatory and normal conditions associated with changes in pro-inflammatory and anti-inflammatory microglia markers (Wang et al., 2018). Patnala et al. (2017) also observed an alteration of the H3K9ac enrichment and transcription at the promoters of genes related to microglia activation (Tnf- $\alpha$, Nos2, Stat1, IL6, and IL10) after SB treatment. In a microglia model of middle cerebral artery occlusion (MCAO), an upregulation of $\mathrm{H} 3 \mathrm{~K} 9 \mathrm{ac}$ levels was observed, which links $\mathrm{H} 3 \mathrm{~K} 9 \mathrm{ac}$ upregulation to microglial activation in vivo. The same observation was made in post-seizure microglia cells where SAHA pre-treatment reduces the levels of $\mathrm{H} 3$ and H3K9 acetylation to baseline levels (Hu and Mao, 2016).
Inhibitors of HDACs decrease the inflammatory response of isolated microglia exposed to inflammogens such as LPS. HDAC inhibitors treatment also produces a rapid and sustained increase in the level of histone $\mathrm{H} 4$ acetylation in microglia (Durham et al., 2017). Likewise, specific knockdown of Hdac1 and Hdac2 using siRNA was found to reduce LPS-induced microglia activation in vitro (Durham et al., 2017). In the context of regulating the inflammatory response of microglia, these two HDACs show functional redundancy, as an upregulation of HDAC2 expression appears to be able to compensate for HDAC1 deficiency. Of note, these two HDACs are reported to exert both distinct and redundant functions. In fact, with few exceptions, targeted deletion of either Hdac1 or Hdac2 does not cause obvious phenotype in most tissues or cell types (Kelly and Cowley, 2013). Recently, Datta et al. (2018), taking advantage of Cx3cr1Cre $\mathrm{Hdac1}{ }^{f l / f l} \mathrm{Hdac} 2^{f l / f l}$ mouse model, demonstrated that the combined Hdac1 and Hdac2 gene depletion in vivo differentially affected microglia during development, homeostasis and during neurodegeneration. Indeed, whereas Hdac1-2 deletion in adult microglia has no effect on cell number or morphology during homeostasis, in the course of neurodegeneration such as in an AD mice model, Hdac1-2 deletion positively affected microglial phagocytosis of amyloid plaques. Identical genetic intervention in microglia prior to birth also strongly impaired on their development, and resulted in reduced cell number and altered morphology (Datta et al., 2018). Transcriptome analysis revealed that at birth 4,338 genes were differentially expressed in Hdac1-2 null mice as compared to wild-type mice, the number of differentially regulated genes appeared to decrease overtime, suggesting that HDAC1 and HDAC2 are key players for microglia development.

Genome-wide profiling for histone H3 lysine K9 and K27 acetylation, revealed that the global levels of $\mathrm{H} 3 \mathrm{~K} 9 \mathrm{ac}$ and $\mathrm{H} 3 \mathrm{~K} 27 \mathrm{ac}$ are not significantly affected in microglia lacking Hdac1 and Hdac2. Only a deeper inspection revealed that the abundance of $\mathrm{H} 3 \mathrm{~K} 9 \mathrm{ac}$ and $\mathrm{H} 3 \mathrm{~K} 27 \mathrm{ac}$ are increased at the proximal promoters of genes regulating cell cycle and cell activation, e.g., Sema6d, Cdkn2c, Ifnar2, and Kcna3 (Datta et al., 2018). Thus, which histone post-translational modification(s) may account for the significant transcriptional effects of Hdac1-2 deletion in microglia remain to be identified. This identification is a challenge as there is no direct binding of HDAC1/2 to the DNA and also because those proteins are part of several multiprotein complexes in the nucleus i.e., the NuRD (nucleosome remodeling and deacetylation), the Sin3 and the CoREST (co-repressor for element-1-silencing transcription factor) complexes (Kelly and Cowley, 2013).

Enhancer of zeste homolog 2 (EZH2) histone methyltransferase and the catalytic subunit of the Polycomb repressive complex 2 mediate transcriptional silencing through the tri-methylation of the lysine 27 in histone $\mathrm{H} 3$ (H3K27me3). The histone H3K27me3 demethylase Jumonji domain containing 3 (JMJD3, also known as KDM6B) counteracts the effect of EZH2, and therefore the $\mathrm{H} 3 \mathrm{~K} 27 \mathrm{me} 3$ levels are regulated by the balance between activities of EZH2 and JMJD3. In microglia, EZH2 gene expression is found to be significantly and rapidly increased upon a pro-inflammatory stimulus such as LPS-mediated TLR4 
stimulation (Arifuzzaman et al., 2017; Zhang et al., 2018). Remarkably, JMJD3 expression is found to be up-regulated upon IL-4 treatment which promotes alternative microglial activation (Tang et al., 2014), but as well LPS-treatment (Lee et al., 2014; Das et al., 2017). These observations suggest that M1- and M2-stimuli differentially regulate microglial $\mathrm{H} 3 \mathrm{~K} 27 \mathrm{me} 3$ expression level, and thereby these microglia activation states (Figure 1). In fact, inhibition of EZH2 with the selective small molecule inhibitors EPZ-6438, GSK343, or GSK126 suppressed the expression of genes mediating the pro-inflammatory response (Koellhoffer et al., 2014, 2015; Arifuzzaman et al., 2017; Zhang et al., 2018). Moreover, inhibition of EZH2 with GSK343 in the presence of an IL-4 stimulus results in a significant upregulation of M2related genes (Koellhoffer et al., 2014, 2015). Furthermore, Ezh2 deficiency in microglia in vivo, achieved by crossing Ezh2 floxed mice with Cx3cr1-CreER mice, confirmed in an animal model of experimental autoimmune encephalomyelitis, that EZH2 facilitates activation of microglia toward a pro-inflammatory M1 phenotype (Zhang et al., 2018). Mechanistically, EZH2 has been proposed to directly target and repress the expression of gene encoding for suppressor of cytokine signaling 3 (SOCS3), known to promote the proteosomal degradation of tumor necrosis factor receptor-associated factor 6 (TRAF6), key component of the TLR-induced MyD88-dependent NF-kB activation contributing to acquisition of the microglial pro-inflammatory phenotype (Zhang et al., 2018). In addition, EZH2 also appears to regulate positively the expression of the transcription factors interferon regulatory factor (IRF) 1, IRF8, and signal transducer and activator of transcription 1 (STAT1), which have known roles in regulating inflammation (Arifuzzaman et al., 2017). In summary, the H3K27 histone tri-methyltransferase activity of EZH2 promotes M1 microglia polarization but represses M2 microglia polarization.

In contrast, the histone $\mathrm{H} 3 \mathrm{~K} 27 \mathrm{me} 3$ demethylase activity of JMJD3 appears to promote M2 microglia polarization but represses M1 microglia polarization. At first, the observation that JMJD3 expression is found to be increased in microglia upon stimulation with an inflammogen may sound contradictory to a role in repressing a pro-inflammatory activation of these cells. However, if one considers a negative-regulatory loop induced upon M1 stimulation, the effects of JMJD3 can be explained and supported by the existing literature. Indeed, JMJD3 depletion or inhibition in microglia leads to an inhibition of the polarization of microglia into a M2 phenotype and increases the M1 inflammatory response of microglia in vitro (Tang et al., 2014; Das et al., 2017). In addition, dehydroepiandrosterone, one the most abundant circulating steroid hormone in humans, is reported to inhibit LPS-induced microglia-mediated inflammation by further increasing JMJD3 expression level above the one induced by LPS treatment alone (Alexaki et al., 2017), suggesting that JMJD3 expression levels are of importance in regulating microglia polarization. Interestingly, knockdown of Jmjd3 gene per se is sufficient to compromise the expression of various M2 genes, including Arg1, CD206, and $I g f 1$ genes, suggesting that the regulation of microglia M2 polarization by JMJD3 is an intrinsic and cell autonomous mechanism. Suppression of JMJD3 expression per se also induces

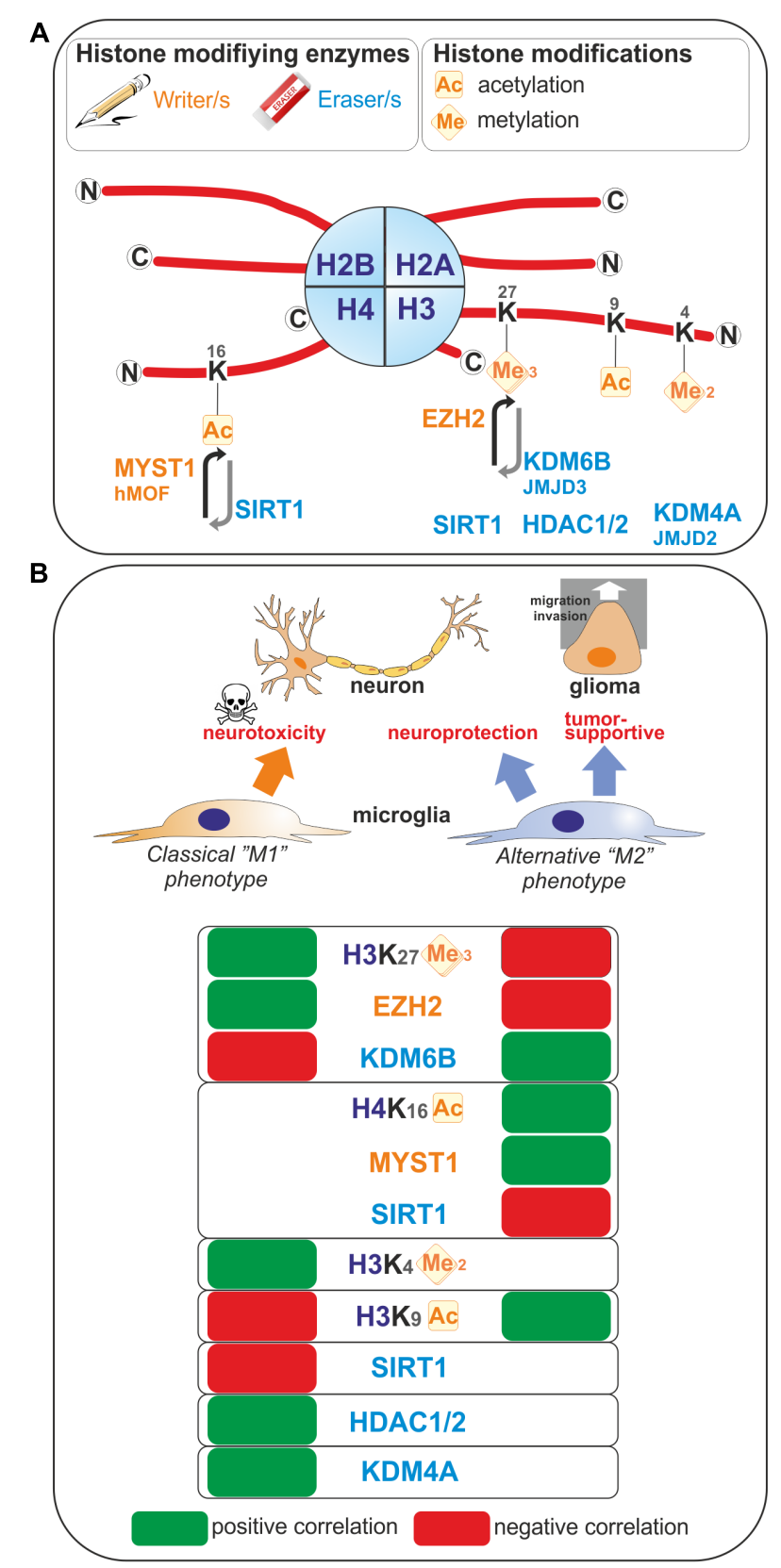

FIGURE 1 | Histone modifications occurring upon microglia polarization. (A) Post-translational modifications on histone tails that occur in microglia are represented. These covalent modifications are added or removed by histone modifying enzymes often referred as writers and erasers. (B) Positive or negative correlation for the expression levels of these histone modifications or the enzymes regulating those histone marks with the polarization toward so-called "M1" or "M2" microglia phenotypes are reported. Ac, Acetylated; me, methylated.

an exaggerated polarization of microglia into M1 phenotype as illustrated by the expression of genes of pro-inflammatory factors including iNOS, IL1 $\beta$, and IL6. Finally, in vivo, in an animal model of PD, the suppression of Jmjd3 in the substantia nigra was shown to promote microglial over-activation and 
thereby exacerbate dopamine neuron loss (Tang et al., 2014). Of note, controversial observation of JMJD3 role has been observed in microglia. Indeed, by transcriptional sequencing analysis of the effect of the JMJD3 inhibitor GSK-J4 on primary microglia cells and BV2 microglia cells, Das et al. (2017) showed that this inhibitor have a selective effect on the expression of genes induced by LPS since it suppresses the induction of chemokines and cytokines, of transcription factors and interferon-stimulated genes. Moreover, it is shown that STAT1 and STAT3 are regulating JMJD3 transcription and cooperates with this transcription factor to induce pro-inflammatory genes expression (Przanowski et al., 2014).

The H3K9ac histone mark which, when located near the transcription start site is essentially related to transcription activation, has been linked to microglia activation (Figure 1). Indeed, in primary and BV2 microglia cells, acetate treatment induces $\mathrm{H} 3 \mathrm{~K} 9$ hyperacetylation, reverses LPS-induced H3K9 hypoacetylation (Soliman et al., 2012) and increases the amount of acetylated H3K9 bound to the promoter regions of Cox1, Cox2, IL1 $\beta$, and NFKB p65 genes (Soliman et al., 2013). An increase of $\mathrm{H} 3 \mathrm{~K} 9 \mathrm{ac}$ has also been found in microglia in a model of neuropathic pain. In this model, the authors study the benefit of exercise on neuropathic pain. By investigating the nuclear expression of $\mathrm{H} 3 \mathrm{~K} 9 \mathrm{ac}$ in microglia, it has been shown that, in a mice model of partial sciatic nerve ligation (PSL), running exercise increased significantly the number of microglia expressing acetylated $\mathrm{H} 3 \mathrm{~K} 9$ compared to sedentary mice suggesting a role of $\mathrm{H} 3 \mathrm{~K} 9$ acetylation in producing exerciseinduced hypoalgesia (Kami et al., 2016).

Methylation of histone 3 on lysine 4 residue is linked to active transcription. $\mathrm{H} 3 \mathrm{~K} 4 \mathrm{me} 2$ is defined as a specific mark for promoters and enhancers (He et al., 2010; Kaikkonen et al., 2013), while acetylation of $\mathrm{H} 3 \mathrm{~K} 27$ corresponds to their transcriptional activity (Creyghton et al., 2010). By analysis of the transcriptomes and enhancer landscapes of resident macrophages and microglia using ATAC-seq and ChIP-seq approaches, Gosselin et al. (2014) revealed the existence of specific pattern for $\mathrm{H} 3 \mathrm{~K} 4 \mathrm{me} 2$ deposition in microglia, which substantially differs from that of large peritoneal macrophages. Moreover, by identifying a new type of microglia, Disease associated microglia or DAM, Keren-Shaul et al. (2017) suggested a role of H3K4me2 in the priming of microglia. Indeed, by using a specific method of ChIP-sequencing with high sensitivity and comparing enhancers from DAM and microglia in wild-type or Alzheimer disease mouse model, they observed a highly similar global pattern of $\mathrm{H} 3 \mathrm{~K} 4 \mathrm{me} 2$, which is present at promoters and enhancers regions. For DAMspecific genes, the authors also observed that active H3K4me2 regions are present in DAM but also in microglia. This suggests that homeostatic microglia already contains the DAM program (Keren-Shaul et al., 2017).

In opposition to the JMJD family, the histone lysine demethylases enzymes (KDM) catalyze the removal of methyl marks from histone lysine residues which leads to the regulation of the structure of the chromatin and the gene expression by epigenetic changes. By LPS treatment activation, BV2 cells and primary microglia cells showed an upregulation of the JMJD2 (also known as KDM4A) and KDM1A enzymes, respectively (Das et al., 2015b, 2016). Moreover, stimulation of microglia cells by TLR3- and TLR4 ligands results in an upregulation of the JMJD2 enzyme in the BV2 microglia cell line (Das et al., 2015a).

Little is known concerning histone phosphorylation in microglia. One study focused on Endocannabinoids which are supposed to reduce neuronal damage after their release in the case of brain injury. In this context, Eljaschewitsch et al. (2006) showed that in microglia, the cannabinoid receptor pathway $(\mathrm{CB} 1 / 2)$ and the production of MKP-1 (via the phosphorylation of Histone $\mathrm{H} 3$ ) lead to the suppression of iNOS expression and NO production. The authors conclude that the AEA endocannabinoid activates the phosphorylation of the histone $\mathrm{H} 3$ and subsequently the expression of MKP-1 which will lead to block the release of NO only in microglia treated with LPS, leading to neuroprotection (Eljaschewitsch et al., 2006).

Sirtuin 1 (SIRT1) is involved in different cellular processes like inflammation or aging/senescence (Gan and Mucke, 2008; Libert and Guarente, 2013). SIRT1 acts as a deacetylase enzyme with different intracellular targets like histones among others (Michan and Sinclair, 2007; Zhang et al., 2011). Cho S.H. et al., 2015 reported a reduction of SIRT1 with the aging of microglia. This SIRT1 reduction can be associated with aging but also with memory deficits mediated by Tau via the upregulation of IL-1 $\beta$ in mice (Cho S.H. et al., 2015). Moreover, we recently studied the epigenetic changes occurring in microglia under the influence of brain tumor cells (glioma cells). By using a coculture system between microglia and glioma cells we observed that the activation of microglia by glioma cells induces an increase of $\mathrm{H} 4 \mathrm{~K} 16 \mathrm{ac}$ in microglia. This is due to the increase of SIRT1 into the nucleus of microglia cells which will deacetylates hMOF (a H4K16 acetyltransferase) leading to its chromatin recruitment at the promoter of specific microglia target genes (Saidi et al., 2018; Figure 1).

\section{MICRORNA AND LONG NON-CODING RNA}

Non-coding RNAs (ncRNAs), including long non-coding RNAs (lncRNAs) and microRNAs (miRNAs/miRs) serve important roles in regulating the expression of certain genes (Patil et al., 2014) and have emerged as epigenetic regulators of biological processes in microglia.

MicroRNAs are small (20-30 nucleotides in length), highly conserved ncRNAs that regulate gene expression posttranscriptionally. They bind to the $3^{\prime}$-UTR (untranslated region) of their mRNAs target(s) and thereby downregulate gene expression through the RNA interference pathway. Worth a notice, miRNAs are involved in the fine-tuning regulation of the expression of around $30 \%$ of all mammalian protein-encoding genes.

In fact, microglial steady-state as well as the different microglia activation states can be characterized by distinct miRNA signatures. Indeed, Butovsky et al. (2014) uncovered, using a Nanostring based miRNA chip that contains 600 microRNAs, that eight of these microRNAs, i.e., miR-29a, mIR-29b, miR-30a, miR-99a, miR-103, miR-125b, miR-322, and miR-342 are highly 
expressed in unchallenged mouse microglia. Furthermore, three of those (miR-99a, miR-125b, and miR-342) were found to have a microglial specific expression compared to other immune cells (Butovsky et al., 2014).

The role of miRNAs in regulating the microglial activation has been investigated in the context of multiple stimuli, brain challenges and diseases. For simplicity, the M1/M2 paradigm is used in this review when reporting the effect of various miRNAs on microglial activation states. The current literature does not allow for most of the reports a more detailed definition of the microglia phenotypes. In order to elucidate the role miRNAs may exert on the acquisition of the M1 versus M2 microglial phenotypes, Freilich et al. (2013) performed miRNAs expression profiling on primary murine microglia exposed to lipopolysaccharide (M1-like condition) or interleukin-4 (M2-like condition). Using a mouse miRNA Array that interrogates 690 pre-miRNAs and 722 mature miRNAs, they revealed that: (1) upon lipopolysaccharide stimulation of microglia, 12 miRNAs were increased and 35 were reduced; (2) upon interleukin-4 stimulation of microglia, 16 miRNAs were increased and 28 were decreased. In this study, miR-155 and miR-145 were identified as the most significantly up-regulated miRNAs in the context of lipopolysaccharide-stimulation of microglia and interleukin4 -stimulation of microglia, respectively. The differentiation regulation of miR-155 and miR-145 expression in microglial M1 versus M2 phenotypes, has been confirmed in the context of other stimuli promoting those phenotypes (Cardoso et al., 2012; Woodbury et al., 2015; Qi et al., 2017; Xie et al., 2017; Yin H. et al., 2017). The microRNA miR-155 has gained particular attention in the context of ALS. Indeed, in the SOD1 ${ }^{G 93 A}$ mouse model of ALS, overexpressing the human SOD1 gene carrying a glycine to alanine point mutation at residue 93 (G93A), increased microglial miR-155 expression in the pre-symptomatic mice suggests that this miR could be used as a marker to track ALS at an early stage. In contrast, other microRNAs, such as miR-125b, miR146a, and miR-124, were only found to be upregulated at the symptomatic stage (Cunha et al., 2018). Furthermore, targeting miR-155 appears to restore microglia function and prolongs survival of the SOD1 $1^{G 93 A}$ mice (Koval et al., 2013; Butovsky et al., 2015). Further, significant down-regulation of miR-689 was found to associate with the M1-activation phenotype, whereas down-regulation of miR-711 associated with the M2activation phenotype. Remarkably, reduced miR-124 expression was observed upon activation toward both phenotypes suggesting that miR-124 expression may be associated to the microglia steady-state and thus to be added to the miRNAs microglial signature described by Butovsky and coworkers (Butovsky et al., 2014).

Of the potential epigenetic regulators that can control microglia biology, miRNAs are probably the most investigated one. Illustration of these considerable efforts are depicted in Table 1 that report the different miRNAs, as well as their target genes, which have been reported to affect microglia activation.

In addition to miRNAs, IncRNAs, which are a type of ncRNAs that exceed 200 nucleotides in length, have also emerged as potential factors contributing to the regulation of microglia activation states. IncRNAs H19, MALAT1,
Gm4419, and SNHG14 have been reported to stimulate the activation of microglia toward the M1 phenotype and thereby promote neuroinflammation (Qi et al., 2017; Wang et al., 2017; Wen et al., 2017; Han et al., 2018; Zhou H.J. et al., 2018), IncRNAs GAS5 has an inhibitory effect on M2 polarization of microglia and increases demyelination (Sun et al., 2017).

\section{DNA METHYLATION}

DNA methylation is a chemical chromatin modification occurring on the cytosine residues from CpGs dinucleotides. DNA methylation leads to repression of gene transcription when $\mathrm{CpG}$ islands (regions of the genome containing high density of CpGs) are methylated (Goll and Bestor, 2005). DNA methylation corresponds to the addition of a methyl group on the targeted cytosine from a CpG dinucleotide. Once methylated, the cytosine is referred as 5-methyl cytosine or 5-mC. During gametogenesis and embryogenesis, DNA methylation plays a major role in regulating the chromatin organization and the expression of genes. (Goll and Bestor, 2005; Surani et al., 2008). DNA methylation patterns are regulated by specific enzymes called DNA methyltransferases or DNMTs which can act as de novo or maintenance DNA methylation enzymes.

De novo DNA methyltransferases add methyl groups after the replication of the DNA while maintenance methyltransferases will act on hemi-methylated DNA during the replication of the DNA (Prokhortchouk and Defossez, 2008). Ten-eleven translocase (TETs) family enzymes catalyze 5-mC marks to 5-hmC (5-hydroxymethylcytosine), which corresponds to an active demethylation process leading to an increase of gene expression (Tahiliani et al., 2009). DNA methylation is involved in different cellular processes. Indeed, DNA methylation regulates the $\mathrm{X}$ chromosome inactivation, the silencing of centromeric and repetitive sequences but also mammalian imprinting showing the importance of DNA methylation in term of stable and heritable epigenetic regulation (Bestor, 2000; Li, 2002; Reik, 2007).

In contrast to the extensive investigations made on the effect of HDACs inhibitors on microglial gene expression, the regulation of gene expression by DNA methylation is poorly studied in those cells. Two different approaches have been used to investigate the impact of DNA methylation in microglia. This epigenetic modification has been investigated either at the global level, looking for changes in total DNA methylation, or at selected targeted sites, looking at specific gene methylation and related gene expression.

Few studies focused on the global level of DNA methylation in the brain associated to specific brain injury or disease. By immunochemistry, a global hypermethylation has been observed in $\mathrm{AD}$ brain and also a significant increase of 5 -hmC in the middle frontal gyrus and middle temporal gyrus of human AD brain (Coppieters et al., 2014). The authors also observed that the levels of 5 - $\mathrm{mC}$ and 5 -hmC were low in microglia in control and $\mathrm{AD}$ brains. This confirms the observation made 
by Phipps et al. (2016) whom have shown no differences in $5-\mathrm{mC}$ or $5-\mathrm{hmC}$ in $\mathrm{AD}$ in microglia or interneurons. Moreover, no differences were observed in 5 - $\mathrm{mC}$ or 5 -hmC in cells in plaque free regions or near the plaque in late $\mathrm{AD}$ (Phipps et al., 2016). So even if AD is associated with microglia activation, it seems that global DNA methylation changes occurring during the disease need to be investigated further in order to confirm a role of DNA methylation in microglia. On the opposite, global methylation changes in microglia has been observed in a rat model of traumatic brain injury (TBI). In this model, by using an immunohistochemistry and a double staining approaches, a sub-population of reactive microglia has been identified and this population is characterized as the major source of hypomethylated cells (Zhang et al., 2007).
When focusing on specific gene methylation, it has been shown that IL1 $\beta$ gene expression is regulated by DNA methylation in aging microglia. Indeed, IL1 $\beta$ gene hypomethylation is associated with upregulation of the cytokine production in two different models of aging. In the first one, the authors associated SIRT1 deficiency to an upregulation of IL1 $\beta$ by hypomethylation of specific CpGs sites on IL1 $\beta$ proximal promoter (Cho S.H. et al., 2015). Matt et al. (2016) confirmed that IL1 $\beta$ upregulation is due to its hypomethylation and validates the role of DNA methylation by treating BV2 and primary microglia cells with the DNA methylation inhibitor 5-azacytidine which increased IL1 $\beta$ gene expression.

In $\mathrm{AD}, \mathrm{S}$-Adenosylhomocysteine $(\mathrm{SAH})$, is a potent inhibitor of methyltransferases. SAH increases the production of amyeloid$\beta$ in BV2 microglia cells possibly by increasing the expression

TABLE 1 | MicroRNAs regulating microglia activation and their gene targets.

\begin{tabular}{|c|c|c|c|}
\hline Function & miRNA & Gene target & Reference \\
\hline \multirow{20}{*}{$\begin{array}{l}\text { Negative regulator of microglial } \\
\text { pro-inflammatory activation }\end{array}$} & $\operatorname{miR}-7$ & NLRP3 & Zhou Y. et al., 2016 \\
\hline & miR-26a & ATF2 & Kumar et al., 2015 \\
\hline & miR-27a & TLR4, IRAK4 & Lv et al., 2017 \\
\hline & $\mathrm{miR}-30 \mathrm{a}$ & NEUROD1 & Fu et al., 2018 \\
\hline & miR-93 & & Tian et al., 2017 \\
\hline & $\operatorname{miR}-124$ & RFX1 & $\begin{array}{l}\text { Dong et al., 2016; Guo et al., 2016; Hamzei Taj et al., 2016a; Feng } \\
\text { et al., 2017; Cunha et al., } 2018\end{array}$ \\
\hline & $\operatorname{miR}-125 b$ & STAT3 & Parisi et al., 2013; Cunha et al., 2018 \\
\hline & $\mathrm{miR}-128$ & & Yang et al., 2017 \\
\hline & $\operatorname{miR}-145$ & PLA2G4A & Qi et al., 2017 \\
\hline & $\operatorname{miR}-146 a$ & & $\begin{array}{l}\text { Sharma et al., 2015; Zhou et al., 2015; Zhao et al., 2016; Deng et al., } \\
\text { 2017; Cunha et al., } 2018\end{array}$ \\
\hline & $\operatorname{miR}-181 \mathrm{c}$ & MLL1 & Ma et al., 2016; Yin M. et al., 2017 \\
\hline & miR-199b & $I K K \beta$ & Zhou et al., 2016 \\
\hline & miR-200b & $J U N$ & Jadhav et al., 2014 \\
\hline & miR-203 & MYD88 & Yang et al., 2015 \\
\hline & miR-339 & $I K K \beta, I K K e$ & Zhang et al., 2014 \\
\hline & miR-365 & IL6 & Parisi et al., 2013 \\
\hline & miR-367 & IRAK4 & Yuan et al., 2015 \\
\hline & $\mathrm{miR}-424$ & CDC25A, CCND1, CDK6 & Zhao et al., 2013; Liu et al., 2015 \\
\hline & miR-Let-7a & & Cho K.J. et al., 2015 \\
\hline & miR-Let-7c & CASP3 & Lv et al., 2018 \\
\hline \multirow{9}{*}{$\begin{array}{l}\text { Positive regulator of microglial } \\
\text { pro-inflammatory activation }\end{array}$} & $\operatorname{miR}-9$ & MCPIP1 & Yao et al., 2014 \\
\hline & miR-29b & TNFAIP3 & Thounaojam et al., 2014 \\
\hline & $\operatorname{miR}-145$ & $N R 4 A 2$ & Xie et al., 2017 \\
\hline & $\operatorname{miR}-155$ & RACK 1, SOCS-1 & $\begin{array}{l}\text { Cardoso et al., 2012; Butovsky et al., 2015; Woodbury et al., 2015; Yin } \\
\text { H. et al., } 2017\end{array}$ \\
\hline & $\operatorname{miR}-195$ & ATG14 & Shi et al., 2013 \\
\hline & miR-204 & SIRT1 & Li et al., 2015 \\
\hline & miR-206 & IGF1 & Xing et al., 2016 \\
\hline & $\operatorname{miR}-221$ & SOCS1 & Xia et al., 2016 \\
\hline & $\operatorname{miR}-7116$ & $T N F \alpha$ & He et al., 2017 \\
\hline \multirow[t]{3}{*}{$\begin{array}{l}\text { Positive regulator of microglial } \\
\text { anti-inflammatory activation }\end{array}$} & $\operatorname{miR}-124$ & RAC1 & $\begin{array}{l}\text { Brennan et al., 2016; Hamzei Taj et al., 2016b; Louw et al., 2016; } \\
\text { Svahn et al., } 2016\end{array}$ \\
\hline & miR-Let-7a & & Song et al., 2015 \\
\hline & miR-Let-7c & CASP3 & Ni et al., 2015 \\
\hline
\end{tabular}




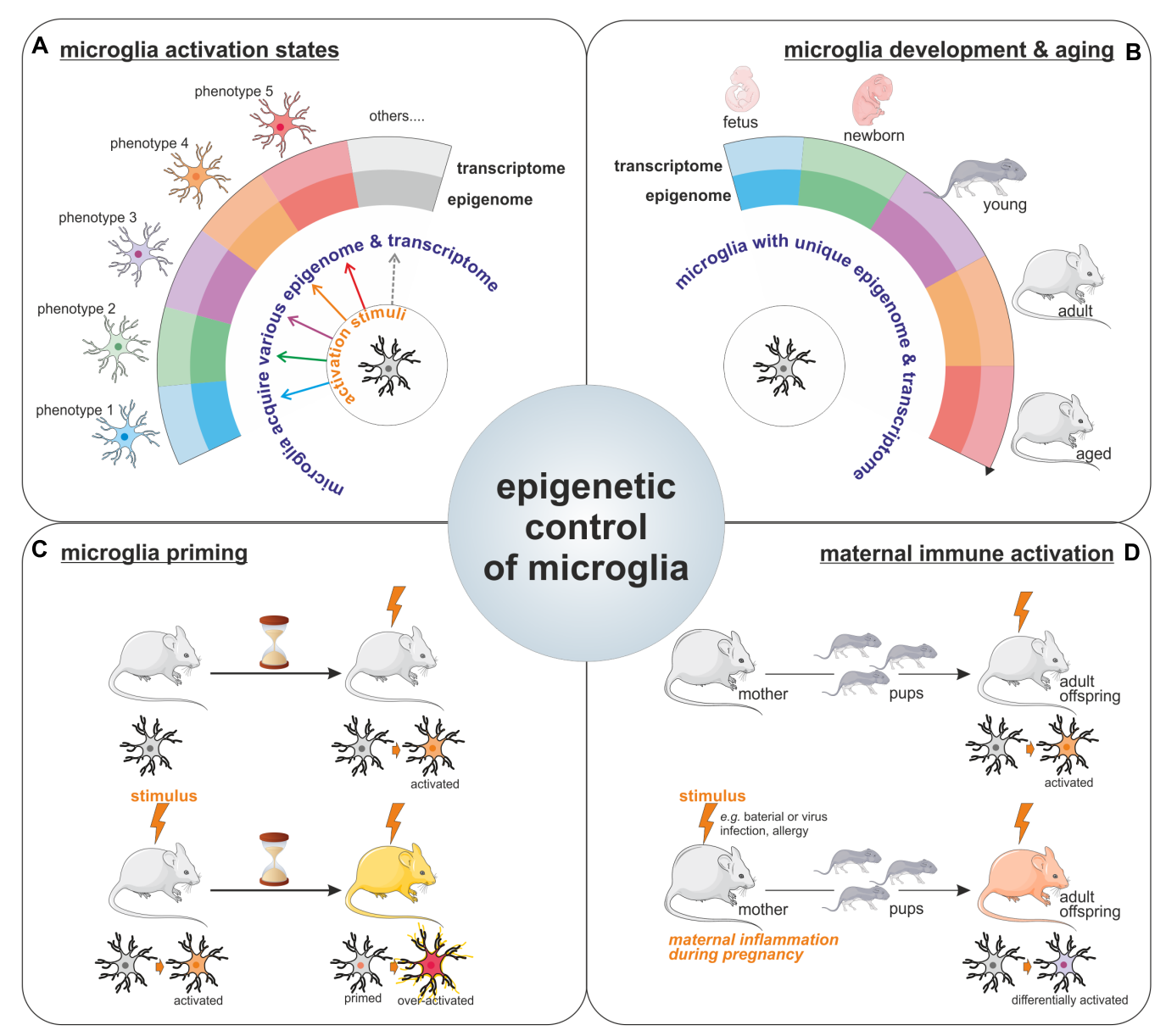

FIGURE 2 | Epigenetic control of microglia. Illustration of the importance for epigenetics mechanisms for the acquisition of microglia activation states in response to various stimuli (A), for the definition of unique microglial molecular signatures throughout life, including microglia development and aging (the different microglia colors represents the different phenotypes these cells can harbor like pro-inflammatory/wound healing/pro-tumoral phenotypes among others) (B), as well as for the long-lasting effect observed on microglia phenotypes such as in the context of microglial priming (C) or upon maternal immune activation (D).

of amyloid precursor protein (APP) via the promotion of hypomethylation of the APP and PS1 gene promoters (Lin et al., 2009). Although SAH only significantly increased the expression of BACE1 (beta-site APP cleaving enzyme 1) at the highest concentration used, Byun et al. (2012) uncovered two specific methylation sites of Bace1 in BV2 microglia cells. By using a bisulfite sequencing approach, they showed that after treatment of BV2 cells with 5-Azacytidine, the Bace1 gene presented specific demethylation of two CpG sites (+298 and +351) in its 5'-UTR region. Mitochondrial dysfunction has been implicated in the pathogenesis of PD. Indeed, in brain tissue from PD patients, a reduction of the expression of PGC- $1 \alpha$ (peroxisome proliferatoractivated receptor gamma coactivator-1) has been observed. Su et al. (2015) investigated the $P G C-1 \alpha$ promoter methylation after activation of neuroinflammation by the pro-inflammatory acid palmitate. They observed that palmitate induces PGC$1 \alpha$ promoter methylation in microglia cells as well as mouse primary cortical neurons and astrocytes which reduces the expression of the gene and reduces the mitochondrial content (Su et al., 2015). Finally, it is shown that a specific DNMT is involved in microglia activation. Indeed, by transcriptome sequencing approaches, DNMT3L is found upregulated after microglia activation either by LPS treatment or by stimulation of microglia with TLR3 and TLR4 ligands (Das et al., 2015a,b).

\section{PERSPECTIVES}

For a long period of time, microglia have been considered as cells capable of polarization into two distinct phenotypes (so called M1 and M2 phenotypes), however, nowadays it is clear that microglia can multiple phenotypes and that the regulation of microglia activation is far more complicated than initially described. The transcriptional and epigenetic machineries have emerged as important regulators of microglia phenotype acquisition (Figure 2A). Indeed, specific transcriptome profiles have been shown to define the distinct microglial phenotypes acquired in response to various stimuli or challenges with the CNS (Holtman et al., 2017). Collectively the above-mentioned reports 
strongly support the contribution of epigenetic mechanisms to the acquisition of these different microglial activation states. Worth a notice, even in the context of the unchallenged brain, microglia exhibit different transcriptome throughout life (Butovsky et al., 2014; Figure 2B). Moreover, surveying microglia as well as activated ones can be characterized by distinct miRNA signatures (Butovsky et al., 2014). Thus, it seems that unique epigenome and transcriptome can define the different microglia states of activation in the developing, aging, and diseased brain. Furthermore, a recent study illustrated the idea that since microglia possess different epigenomes and associated transcriptomes throughout life, and in the course of diseases, intervention of the epigenetics machinery could therefore have different impacts on these cells. In fact, Hdacl and Hdac2 depletion in microglia led to contrasting effects in the developing, the homeostatic and the diseased brain (Datta et al., 2018).

The involvement of epigenetic mechanisms in the control of microglia polarization toward a specific phenotype or activation state raises the question; how long microglia can be affected by such epigenetic changes? Since microglia are capable of both innate and adaptive responses, it has been proposed that they can acquire a memory of particular events. Indeed, there are compelling evidences for a microglial epigenetic memory, which is illustrated by the observed differential response to a challenge by microglia, which have been previously exposed to the same or a different challenge, as compared to the response of naive microglia. This process is known in the field as the microglia priming (Figure 2C). For example, priming of microglia with a LPS stimulus leads to a different response to a second stimuli (Liu et al., 2012). This epigenetic memory of primed microglia has been confirmed in a model of long-lasting pro-inflammatory suppression where the microglia presents an immune-suppressed phenotype acquired by epigenetic changes after LPS-preconditioning (with a reduction in $\mathrm{H} 3 \mathrm{~K} 4 \mathrm{me} 3$ on IL1- $\beta$ and TNF- $\alpha$ promoters) to prevent excessive damages (Schaafsma et al., 2015). This acquired memory by microglia after priming is also observed in vivo in the case of development and aging where IL10 gene, for example, is specifically regulated by methylation in the adult after an early life drug experience (Schwarz et al., 2011). Epigenetic regulation is also involved in microglia memory during development since pre-exposed microglia to LPS in vivo shown different patterns of gene expression including HDACs prior and after a second exposure to LPS in vitro (Cao et al., 2015). Recently, immune memory of microglia has been observed in vivo after inflammatory stimuli. In their model, Wendeln and coworkers observe that priming of microglia leads to an acute immune training and tolerance in the brain, that microglia are reprogrammed epigenetically and that these changes could be involved in differential responses to neuropathology (Wendeln et al., 2018).

It is known that epigenetic modifications are heritable marks like DNA methylation and can be sustained in time but also into generations. This brings the point on a long term regulation of microglia by epigenetic modifications or signatures. It is very interesting to observe the heritable phenotypes of microglia through the generations. In mammals, maternal immune activation, or MIA, which can be due to an inflammatory stimulus like bacterial or viral infections but also activated after allergy during the pregnancy, has been shown to positively correlates with the risk of developing neuropsychiatric disorders like autism in the offspring (Vogel Ciernia et al., 2018). This link may be bridged to an impact of MIA on the microglia from the fetus which leads to the acquisition of functional changes that are maintained in the adult (Mattei et al., 2017; Prins et al., 2018; Figure 2D). In a majority of animal models of maternal immune activation, the rat dams or pregnant mice are treated with either a viral mimetic (poly I:C) or LPS. Microglia in offspring from MIA challenged rodent show an altered transcriptome signature, with increased expression of genes related to proinflammatory signaling pathways, but a reduction in expression of genes related to proliferation and cell cycle (Ben-Yehuda et al., 2017; Mattei et al., 2017). The transgenerational effect of MIA, has led to the proposal that microglia epigenetic changes, that can induce long-term modification of microglia phenotype, should be responsible for the observed effect in progenies (Nardone and Elliott, 2016). Indeed, recent study shows alteration of the microglial DNA methylome in a mouse asthma model of MIA. Genome wide analysis identified alteration in the expression of genes involved in the control of microglial sensitivity to the environment and in the shaping of neuronal connections in the developing brain (Vogel Ciernia et al., 2018).

Finally, one should keep in mind that it is highly improbable that the control of microglia plasticity is limited to epigenetic mechanisms. For example, metabolic changes in the microglia and its microenvironment have been linked to microglia phenotype polarization and associated to various diseases (Gimeno-Bayon et al., 2014; Kalsbeek et al., 2016; Orihuela et al., 2016). Thus, there is a multifactorial regulation of microglia activation states, and this level of complexity should be taken into account when designing potential therapeutic strategies targeting microglial epigenetic mechanisms.

\section{AUTHOR CONTRIBUTIONS}

MC and BJ planned and wrote the manuscript.

\section{FUNDING}

This work has been supported by grants from the TracInflam grant from ERA-NET NEURON Neuroinflammation, the Swedish Research Council, the Swedish Childhood Cancer Foundation, the Swedish Cancer Foundation, the Swedish Cancer Society, and the Swedish Brain Foundation.

\section{ACKNOWLEDGMENTS}

We apologize to authors whose primary references could not be cited owing to space limitations. 


\section{REFERENCES}

Abdanipour, A., Schluesener, H. J., and Tiraihi, T. (2012). Effects of valproic acid, a histone deacetylase inhibitor, on improvement of locomotor function in rat spinal cord injury based on epigenetic science. Iran. Biomed. J. 16, 90-100.

Alexaki, V. I., Fodelianaki, G., Neuwirth, A., Mund, C., Kourgiantaki, A., Ieronimaki, E., et al. (2017). DHEA inhibits acute microglia-mediated inflammation through activation of the TrkA-Akt1/2-CREB-Jmjd3 pathway. Mol. Psychiatry 23, 1410-1420. doi: 10.1038/mp.2017.167

Arifuzzaman, S., Das, A., Kim, S. H., Yoon, T., Lee, Y. S., Jung, K. H., et al. (2017). Selective inhibition of EZH2 by a small molecule inhibitor regulates microglial gene expression essential for inflammation. Biochem. Pharmacol. 137, 61-80. doi: 10.1016/j.bcp.2017.04.016

Ben-Yehuda, H., Matcovitch-Natan, O., SpinradI, A., Amit, I., and Schwartz, M. (2017). Maternal immune activation alters microglia proliferation in the developing brain. Brain Behav. Immun. 66:e3. doi: 10.1016/j.bbi.2017.07.026

Bestor, T. H. (2000). The DNA methyltransferases of mammals. Hum. Mol. Genet. 9, 2395-2402. doi: 10.1093/hmg/9.16.2395

Blanchard, F., Kinzie, E., Wang, Y., Duplomb, L., Godard, A., Held, W. A., et al. (2002). FR901228, an inhibitor of histone deacetylases, increases the cellular responsiveness to IL- 6 type cytokines by enhancing the expression of receptor proteins. Oncogene 21, 6264-6277. doi: 10.1038/sj.onc.1205777

Brennan, G. P., Dey, D., Chen, Y., Patterson, K. P., Magnetta, E. J., Hall, A. M., et al. (2016). Dual and opposing roles of microRNA-124 in epilepsy are mediated through inflammatory and NRSF-dependent gene networks. Cell Rep. 14, 2402-2412. doi: 10.1016/j.celrep.2016.02.042

Butovsky, O., Jedrychowski, M. P., Cialic, R., Krasemann, S., Murugaiyan, G., Fanek, Z., et al. (2015). Targeting miR-155 restores abnormal microglia and attenuates disease in SOD1 mice. Ann. Neurol. 77, 75-99. doi: 10.1002/ana. 24304

Butovsky, O., Jedrychowski, M. P., Moore, C. S., Cialic, R., Lanser, A. J., Gabriely, G., et al. (2014). Identification of a unique TGF-beta-dependent molecular and functional signature in microglia. Nat. Neurosci. 17, 131-143. doi: 10.1038/nn.3599

Byun, C. J., Seo, J., Jo, S. A., Park, Y. J., Klug, M., Rehli, M., et al. (2012). DNA methylation of the $5^{\prime}$-untranslated region at +298 and +351 represses BACE1 expression in mouse BV-2 microglial cells. Biochem. Biophys. Res. Commun. 417, 387-392. doi: 10.1016/j.bbrc.2011.11.123

Cao, M., Cortes, M., Moore, C. S., Leong, S. Y., Durosier, L. D., Burns, P., et al. (2015). Fetal microglial phenotype in vitro carries memory of prior in vivo exposure to inflammation. Front. Cell. Neurosci. 9:294. doi: 10.3389/fncel.2015. 00294

Cardoso, A. L., Guedes, J. R., Pereira de Almeida, L., Pedroso, and de Lima, M. C. (2012). miR-155 modulates microglia-mediated immune response by down-regulating SOCS-1 and promoting cytokine and nitric oxide production. Immunology 135, 73-88. doi: 10.1111/j.1365-2567.2011.03514.x

Cho, K. J., Song, J., Oh, Y., and Lee, J. E. (2015). MicroRNA-Let-7a regulates the function of microglia in inflammation. Mol. Cell. Neurosci. 68, 167-176. doi: 10.1016/j.mcn.2015.07.004

Cho, S. H., Chen, J. A., Sayed, F., Ward, M. E., Gao, F., Nguyen, T. A., et al. (2015). SIRT1 deficiency in microglia contributes to cognitive decline in aging and neurodegeneration via epigenetic regulation of IL-1beta. J. Neurosci. 35, 807-818. doi: 10.1523/JNEUROSCI.2939-14.2015

Chung, H., and Sidhu, K. S. (2008). Epigenetic modifications of embryonic stem cells: current trends and relevance in developing regenerative medicine. Stem Cells Cloning 1, 11-21. doi: 10.2147/SCCAA.S3566

Coppieters, N., Dieriks, B. V., Lill, C., Faull, R. L., Curtis, M. A., and Dragunow, M. (2014). Global changes in DNA methylation and hydroxymethylation in Alzheimer's disease human brain. Neurobiol. Aging 35, 1334-1344. doi: 10.1016/ j.neurobiolaging.2013.11.031

Creyghton, M. P., Cheng, A. W., Welstead, G. G., Kooistra, T., Carey, B. W., Steine, E. J., et al. (2010). Histone H3K27ac separates active from poised enhancers and predicts developmental state. Proc. Natl. Acad. Sci. U.S.A. 107, 21931-21936. doi: $10.1073 /$ pnas.1016071107

Cunha, C., Santos, C., Gomes, C., Fernandes, A., Correia, A. M., Sebastiao, A. M., et al. (2018). Downregulated glia interplay and increased miRNA-155 as promising markers to track ALS at an early stage. Mol. Neurobiol. 55, 4207-4224. doi: 10.1007/s12035-017-0631-2
Das, A., Arifuzzaman, S., Yoon, T., Kim, S. H., Chai, J. C., Lee, Y. S., et al. (2017). RNA sequencing reveals resistance of TLR4 ligand-activated microglial cells to inflammation mediated by the selective jumonji H3K27 demethylase inhibitor. Sci. Rep. 7:6554. doi: 10.1038/s41598-017-06914-5

Das, A., Chai, J. C., Kim, S. H., Lee, Y. S., Park, K. S., Jung, K. H., et al. (2015a). Transcriptome sequencing of microglial cells stimulated with TLR3 and TLR4 ligands. BMC Genomics 16:517. doi: 10.1186/s12864-015-1728-5

Das, A., Chai, J. C., Kim, S. H., Park, K. S., Lee, Y. S., Jung, K. H., et al. (2015b). Dual RNA sequencing reveals the expression of unique transcriptomic signatures in lipopolysaccharide-induced BV-2 microglial cells. PLoS One 10:e121117. doi: 10.1371/journal.pone.0121117

Das, A., Kim, S. H., Arifuzzaman, S., Yoon, T., Chai, J. C., Lee, Y. S., et al. (2016). Transcriptome sequencing reveals that LPS-triggered transcriptional responses in established microglia BV2 cell lines are poorly representative of primary microglia. J. Neuroinflammation 13:182. doi: 10.1186/s12974-016-0644-1

Datta, M., Staszewski, O., Raschi, E., Frosch, M., Hagemeyer, N., Tay, T. L., et al. (2018). Histone deacetylases 1 and 2 regulate microglia function during development, homeostasis, and neurodegeneration in a context-dependent manner. Immunity 48, 514.e6-529.e6. doi: 10.1016/j.immuni.2018.02.016

De Carvalho, D. D., You, J. S., and Jones, P. A. (2010). DNA methylation and cellular reprogramming. Trends Cell Biol. 20, 609-617. doi: 10.1016/j.tcb.2010. 08.003

Deng, M., Du, G., Zhao, J., and Du, X. (2017). miR-146a negatively regulates the induction of proinflammatory cytokines in response to Japanese encephalitis virus infection in microglial cells. Arch. Virol. 162, 1495-1505. doi: 10.1007/ s00705-017-3226-3

Dong, N., Xu, B., Shi, H., and Lu, Y. (2016). miR-124 regulates amadori-glycated albumin-induced retinal microglial activation and inflammation by targeting Rac1. Invest. Ophthalmol. Vis. Sci. 57, 2522-2532. doi: 10.1167/iovs.15-18224

Durham, B. S., Grigg, R., and Wood, I. C. (2017). Inhibition of histone deacetylase 1 or 2 reduces induced cytokine expression in microglia through a protein synthesis independent mechanism. J. Neurochem. 143, 214-224. doi: 10.1111/ jnc. 14144

Eggen, B. J., Raj, D., Hanisch, U. K., and Boddeke, H. W. (2013). Microglial phenotype and adaptation. J. Neuroimmune Pharmacol. 8, 807-823. doi: 10. 1007/s11481-013-9490-4

Eljaschewitsch, E., Witting, A., Mawrin, C., Lee, T., Schmidt, P. M., Wolf, S., et al. (2006). The endocannabinoid anandamide protects neurons during CNS inflammation by induction of MKP-1 in microglial cells. Neuron 49, 67-79. doi: 10.1016/j.neuron.2005.11.027

Esteller, M. (2008). Epigenetics in cancer. N. Engl. J. Med. 358, 1148-1159. doi: 10.1056/NEJMra072067

Feng, C. Z., Yin, J. B., Yang, J. J., and Cao, L. (2017). Regulatory factor X1 depresses ApoE-dependent Abeta uptake by miRNA-124 in microglial response to oxidative stress. Neuroscience 344, 217-228. doi: 10.1016/j.neuroscience. 2016.12.017

Fleiss, B., Nilsson, M. K., Blomgren, K., and Mallard, C. (2012). Neuroprotection by the histone deacetylase inhibitor trichostatin $\mathrm{A}$ in a model of lipopolysaccharide-sensitised neonatal hypoxic-ischaemic brain injury. J. Neuroinflammation 9:70. doi: 10.1186/1742-2094-9-70

Freilich, R. W., Woodbury, M. E., and Ikezu, T. (2013). Integrated expression profiles of mRNA and miRNA in polarized primary murine microglia. PLoS One 8:e79416. doi: 10.1371/journal.pone.0079416

Fu, X., Shen, Y., Wang, W., and Li, X. (2018). MiR-30a-5p ameliorates spinal cord injury-induced inflammatory responses and oxidative stress by targeting Neurod 1 through MAPK/ERK signalling. Clin. Exp. Pharmacol. Physiol. 45, 68-74. doi: 10.1111/1440-1681.12856

Gan, L., and Mucke, L. (2008). Paths of convergence: sirtuins in aging and neurodegeneration. Neuron 58, 10-14. doi: 10.1016/j.neuron.2008.03.015

Gimeno-Bayon, J., Lopez-Lopez, A., Rodriguez, M. J., and Mahy, N. (2014). Glucose pathways adaptation supports acquisition of activated microglia phenotype. J. Neurosci. Res. 92, 723-731. doi: 10.1002/jnr.23356

Ginhoux, F., Greter, M., Leboeuf, M., Nandi, S., See, P., Gokhan, S., et al. (2010). Fate mapping analysis reveals that adult microglia derive from primitive macrophages. Science 330, 841-845. doi: 10.1126/science.1194637

Goll, M. G., and Bestor, T. H. (2005). Eukaryotic cytosine methyltransferases. Annu. Rev. Biochem. 74, 481-514. doi: 10.1146/annurev.biochem.74.010904. 153721 
Gosselin, D., Link, V. M., Romanoski, C. E., Fonseca, G. J., Eichenfield, D. Z., Spann, N. J., et al. (2014). Environment drives selection and function of enhancers controlling tissue-specific macrophage identities. Cell 159, 13271340. doi: 10.1016/j.cell.2014.11.023

Guo, M. L., Periyasamy, P., Liao, K., Kook, Y. H., Niu, F., Callen, S. E., et al. (2016). Cocaine-mediated downregulation of microglial miR-124 expression involves promoter DNA methylation. Epigenetics 11, 819-830. doi: 10.1080/15592294. 2016.1232233

Hambardzumyan, D., Gutmann, D. H., and Kettenmann, H. (2016). The role of microglia and macrophages in glioma maintenance and progression. Nat. Neurosci. 19, 20-27. doi: 10.1038/nn.4185

Hamzei Taj, S., Kho, W., Aswendt, M., Collmann, F. M., Green, C., Adamczak, J., et al. (2016a). Dynamic modulation of microglia/macrophage polarization by miR-124 after focal cerebral ischemia. J. Neuroimmune Pharmacol. 11, 733-748.

Hamzei Taj, S., Kho, W., Riou, A., Wiedermann, D., and Hoehn, M. (2016b). MiRNA-124 induces neuroprotection and functional improvement after focal cerebral ischemia. Biomaterials 91, 151-165. doi: 10.1016/j.biomaterials.2016. 03.025

Han, C. L., Ge, M., Liu, Y. P., Zhao, X. M., Wang, K. L., Chen, N., et al. (2018). LncRNA H19 contributes to hippocampal glial cell activation via JAK/STAT signaling in a rat model of temporal lobe epilepsy. J. Neuroinflammation 15:103. doi: 10.1186/s12974-018-1139-z

He, H. H., Meyer, C. A., Shin, H., Bailey, S. T., Wei, G., Wang, Q., et al. (2010). Nucleosome dynamics define transcriptional enhancers. Nat. Genet. 42, 343-347. doi: 10.1038/ng.545

He, Q., Wang, Q., Yuan, C., and Wang, Y. (2017). Downregulation of miR7116-5p in microglia by $\mathrm{MPP}(+)$ sensitizes TNF-alpha production to induce dopaminergic neuron damage. Glia 65, 1251-1263. doi: 10.1002/glia.23153

Holtman, I. R., Skola, D., and Glass, C. K. (2017). Transcriptional control of microglia phenotypes in health and disease. J. Clin. Invest. 127, 3220-3229. doi: 10.1172/JCI90604

Hsing, C. H., Hung, S. K., Chen, Y. C., Wei, T. S., Sun, D. P., Wang, J. J., et al. (2015). Histone deacetylase inhibitor trichostatin A ameliorated endotoxininduced neuroinflammation and cognitive dysfunction. Mediators Inflamm. 2015:163140. doi: 10.1155/2015/163140

Hu, Q. P., and Mao, D. A. (2016). Histone deacetylase inhibitor SAHA attenuates post-seizure hippocampal microglia TLR4/MYD88 signaling and inhibits TLR4 gene expression via histone acetylation. BMC Neurosci. 17:22. doi: 10.1186/ s12868-016-0264-9

Ito, K., Lim, S., Caramori, G., Cosio, B., Chung, K. F., Adcock, I. M., et al. (2002). A molecular mechanism of action of theophylline: induction of histone deacetylase activity to decrease inflammatory gene expression. Proc. Natl. Acad. Sci. U.S.A. 99, 8921-8926. doi: 10.1073/pnas.132556899

Jadhav, S. P., Kamath, S. P., Choolani, M., Lu, J., and Dheen, S. T. (2014). microRNA-200b modulates microglia-mediated neuroinflammation via the cJun/MAPK pathway. J. Neurochem. 130, 388-401. doi: 10.1111/jnc.12731

Kaikkonen, M. U., Spann, N. J., Heinz, S., Romanoski, C. E., Allison, K. A., Stender, J. D., et al. (2013). Remodeling of the enhancer landscape during macrophage activation is coupled to enhancer transcription. Mol. Cell 51, 310-325. doi: 10.1016/j.molcel.2013.07.010

Kalsbeek, M. J., Mulder, L., and Yi, C. X. (2016). Microglia energy metabolism in metabolic disorder. Mol. Cell. Endocrinol. 438, 27-35. doi: 10.1016/j.mce.2016. 09.028

Kami, K., Taguchi, S., Tajima, F., and Senba, E. (2016). Histone acetylation in microglia contributes to exercise-induced hypoalgesia in neuropathic pain model mice. J. Pain 17, 588-599. doi: 10.1016/j.jpain.2016.01.471

Kannan, V., Brouwer, N., Hanisch, U. K., Regen, T., Eggen, B. J., and Boddeke, H. W. (2013). Histone deacetylase inhibitors suppress immune activation in primary mouse microglia. J. Neurosci. Res. 91, 1133-1142. doi: 10.1002/jnr. 23221

Katsushima, K., and Kondo, Y. (2014). Non-coding RNAs as epigenetic regulator of glioma stem-like cell differentiation. Front. Genet. 5:14. doi: 10.3389/fgene. 2014.00014

Kelly, R. D., and Cowley, S. M. (2013). The physiological roles of histone deacetylase (HDAC) 1 and 2: complex co-stars with multiple leading parts. Biochem. Soc. Trans. 41, 741-749. doi: 10.1042/BST20130010

Keren-Shaul, H., Spinrad, A., Weiner, A., Matcovitch-Natan, O., DvirSzternfeld, R., Ulland, T. K., et al. (2017). A unique microglia type associated with restricting development of Alzheimer's disease. Cell 169, 1276.e17-1290.e17. doi: 10.1016/j.cell.2017.05.018

Koellhoffer, E., Grenier, J., Ritzel, R., and McCullough, L. (2015). Inhibition of Ezh2 leads to decreased M1 and enhanced M2 microglia phenotypes. Stroke 46:AT80.

Koellhoffer, E., Ritzel, R., Grenier, J., and McCullough, L. (2014). Tilting the balance of M1/M2 microglial phenotypes: inhibition of Ezh2 leads to decreased M1 and enhanced M2 phenotype. J. Neuroimmunol. 275:157. doi: 10.1016/j.jneuroim. 2014.08.421

Koval, E. D., Shaner, C., Zhang, P., du Maine, X., Fischer, K., Tay, J., et al. (2013). Method for widespread microRNA-155 inhibition prolongs survival in ALS-model mice. Hum. Mol. Genet. 22, 4127-4135. doi: 10.1093/hmg/dd t261

Kumar, A., Bhatia, H. S., de Oliveira, A. C., and Fiebich, B. L. (2015). microRNA-26a modulates inflammatory response induced by toll-like receptor 4 stimulation in microglia. J. Neurochem. 135, 1189-1202. doi: 10.1111/jnc. 13364

Lee, H. T., Kim, S. K., Kim, S. H., Kim, K., Lim, C. H., Park, J., et al. (2014). Transcription-related element gene expression pattern differs between microglia and macrophages during inflammation. Inflamm. Res. 63, 389-397. doi: 10.1007/s00011-014-0711-y

Li, E. (2002). Chromatin modification and epigenetic reprogramming in mammalian development. Nat. Rev. Genet. 3, 662-673. doi: 10.1038/nr g887

Li, L., Sun, Q., Li, Y., Yang, Y., Yang, Y., Chang, T., et al. (2015). Overexpression of SIRT1 induced by resveratrol and inhibitor of miR-204 suppresses activation and proliferation of microglia. J. Mol. Neurosci. 56, 858-867. doi: 10.1007/ s12031-015-0526-5

Libert, S., and Guarente, L. (2013). Metabolic and neuropsychiatric effects of calorie restriction and sirtuins. Annu. Rev. Physiol. 75, 669-684. doi: 10.1146/annurevphysiol-030212-183800

Lin, H. C., Hsieh, H. M., Chen, Y. H., and Hu, M. L. (2009). $\mathrm{S}$-Adenosylhomocysteine increases beta-amyloid formation in BV-2 microglial cells by increased expressions of beta-amyloid precursor protein and presenilin 1 and by hypomethylation of these gene promoters. Neurotoxicology 30, 622-627. doi: 10.1016/j.neuro.2009.03.011

Liu, H. C., Zheng, M. H., Du, Y. L., Wang, L., Kuang, F., Qin, H. Y., et al. (2012). N9 microglial cells polarized by LPS and IL4 show differential responses to secondary environmental stimuli. Cell. Immunol. 278, 84-90. doi: 10.1016/j. cellimm.2012.06.001

Liu, P., Zhao, H., Wang, R., Wang, P., Tao, Z., Gao, L., et al. (2015). MicroRNA424 protects against focal cerebral ischemia and reperfusion injury in mice by suppressing oxidative stress. Stroke 46, 513-519. doi: 10.1161/STROKEAHA. 114.007482

Louw, A. M., Kolar, M. K., Novikova, L. N., Kingham, P. J., Wiberg, M., Kjems, J., et al. (2016). Chitosan polyplex mediated delivery of miRNA-124 reduces activation of microglial cells in vitro and in rat models of spinal cord injury. Nanomedicine 12, 643-653. doi: 10.1016/j.nano.2015.10.011

Lv, J., Zeng, Y., Qian, Y., Dong, J., Zhang, Z., and Zhang, J. (2018). MicroRNA let$7 c-5 p$ improves neurological outcomes in a murine model of traumatic brain injury by suppressing neuroinflammation and regulating microglial activation. Brain Res. 1685, 91-104. doi: 10.1016/j.brainres.2018.01.032

Lv, Y. N., Ou-Yang, A. J., and Fu, L. S. (2017). MicroRNA-27a negatively modulates the inflammatory response in lipopolysaccharide-stimulated microglia by targeting TLR4 and IRAK4. Cell. Mol. Neurobiol. 37, 195-210. doi: 10.1007/ s10571-016-0361-4

Ma, Q., Zhao, H., Tao, Z., Wang, R., Liu, P., Han, Z., et al. (2016). MicroRNA181c exacerbates brain injury in acute ischemic stroke. Aging Dis. 7, 705-714. doi: 10.14336/AD.2016.0320

Matt, S. M., Lawson, M. A., and Johnson, R. W. (2016). Aging and peripheral lipopolysaccharide can modulate epigenetic regulators and decrease IL1beta promoter DNA methylation in microglia. Neurobiol. Aging 47, 1-9. doi: 10.1016/j.neurobiolaging.2016.07.006

Mattei, D., Ivanov, A., Ferrai, C., Jordan, P., Guneykaya, D., Buonfiglioli, A., et al. (2017). Maternal immune activation results in complex microglial transcriptome signature in the adult offspring that is reversed by minocycline treatment. Transl. Psychiatry 7:e1120. doi: 10.1038/tp.2017.80

Michan, S., and Sinclair, D. (2007). Sirtuins in mammals: insights into their biological function. Biochem. J. 404, 1-13. doi: 10.1042/BJ20070140 
Nardone, S., and Elliott, E. (2016). The interaction between the immune system and epigenetics in the etiology of autism spectrum disorders. Front. Neurosci. 10:329. doi: 10.3389/fnins.2016.00329

Ni, J., Wang, X., Chen, S., Liu, H., Wang, Y., Xu, X., et al. (2015). MicroRNA let $-7 \mathrm{c}-5 \mathrm{p}$ protects against cerebral ischemia injury via mechanisms involving the inhibition of microglia activation. Brain Behav. Immun. 49, 75-85. doi: 10.1016/j.bbi.2015.04.014

Orihuela, R., McPherson, C. A., and Harry, G. J. (2016). Microglial M1/M2 polarization and metabolic states. Br. J. Pharmacol. 173, 649-665. doi: 10.1111/ bph.13139

Parisi, C., Arisi, I., D’Ambrosi, N., Storti, A. E., Brandi, R., D’Onofrio, M., et al. (2013). Dysregulated microRNAs in amyotrophic lateral sclerosis microglia modulate genes linked to neuroinflammation. Cell Death Dis. 4:e959. doi: 10. 1038/cddis.2013.491

Patil, V. S., Zhou, R., and Rana, T. M. (2014). Gene regulation by non-coding RNAs. Crit. Rev. Biochem. Mol. Biol. 49, 16-32. doi: 10.3109/10409238.2013.844092

Patnala, R., Arumugam, T. V., Gupta, N., and Dheen, S. T. (2017). HDAC inhibitor sodium butyrate-mediated epigenetic regulation enhances neuroprotective function of microglia during ischemic stroke. Mol. Neurobiol. 54, 6391-6411. doi: 10.1007/s12035-016-0149-z

Phipps, A. J., Vickers, J. C., Taberlay, P. C., and Woodhouse, A. (2016). Neurofilament-labeled pyramidal neurons and astrocytes are deficient in DNA methylation marks in Alzheimer's disease. Neurobiol. Aging 45, 30-42. doi: 10.1016/j.neurobiolaging.2016.05.003

Prins, J. R., Eskandar, S., Eggen, B. J. L., and Scherjon, S. A. (2018). Microglia, the missing link in maternal immune activation and fetal neurodevelopment; and a possible link in preeclampsia and disturbed neurodevelopment? J. Reprod. Immunol. 126, 18-22. doi: 10.1016/j.jri.2018.01.004

Prinz, M., and Mildner, A. (2011). Microglia in the CNS: immigrants from another world. Glia 59, 177-187. doi: 10.1002/glia.21104

Prokhortchouk, E., and Defossez, P. A. (2008). The cell biology of DNA methylation in mammals. Biochim. Biophys. Acta 1783, 2167-2173. doi: 10.1016/j.bbamcr.2008.07.015

Przanowski, P., Dabrowski, M., Ellert-Miklaszewska, A., Kloss, M., Mieczkowski, J., Kaza, B., et al. (2014). The signal transducers Stat1 and Stat 3 and their novel target Jmjd3 drive the expression of inflammatory genes in microglia. J. Mol. Med. 92, 239-254. doi: 10.1007/s00109-013-1090-5

Qi, X., Shao, M., Sun, H., Shen, Y., Meng, D., and Huo, W. (2017). Long noncoding RNA SNHG14 promotes microglia activation by regulating miR-1455p/PLA2G4A in cerebral infarction. Neuroscience 348, 98-106. doi: 10.1016/j. neuroscience.2017.02.002

Reik, W. (2007). Stability and flexibility of epigenetic gene regulation in mammalian development. Nature 447, 425-432. doi: 10.1038/nature05918

Saidi, D., Cheray, M., Osman, A. M., Stratoulias, V., Lindberg, O. R., Shen, X., et al. (2018). Glioma-induced SIRT1-dependent activation of hMOF histone $\mathrm{H} 4$ lysine 16 acetyltransferase in microglia promotes a tumor supporting phenotype. Oncoimmunology 7:e1382790. doi: 10.1080/2162402X. 2017.1382790

Saijo, K., and Glass, C. K. (2011). Microglial cell origin and phenotypes in health and disease. Nat. Rev. Immunol. 11, 775-787. doi: 10.1038/nri3086

Sarlus, H., and Heneka, M. T. (2017). Microglia in Alzheimer's disease. J. Clin. Invest. 127, 3240-3249. doi: 10.1172/JCI90606

Schaafsma, W., Zhang, X., van Zomeren, K. C., Jacobs, S., Georgieva, P. B., Wolf, S. A., et al. (2015). Long-lasting pro-inflammatory suppression of microglia by LPS-preconditioning is mediated by RelB-dependent epigenetic silencing. Brain Behav. Immun. 48, 205-221. doi: 10.1016/j.bbi.2015.03.013

Schwarz, J. M., Hutchinson, M. R., and Bilbo, S. D. (2011). Early-life experience decreases drug-induced reinstatement of morphine CPP in adulthood via microglial-specific epigenetic programming of anti-inflammatory IL-10 expression. J. Neurosci. 31, 17835-17847. doi: 10.1523/JNEUROSCI.3297-11. 2011

Sharma, N., Verma, R., Kumawat, K. L., Basu, A., and Singh, S. K. (2015). miR146a suppresses cellular immune response during Japanese encephalitis virus JaOArS982 strain infection in human microglial cells. J. Neuroinflammation 12:30. doi: 10.1186/s12974-015-0249-0

Shi, G., Shi, J., Liu, K., Liu, N., Wang, Y., Fu, Z., et al. (2013). Increased miR-195 aggravates neuropathic pain by inhibiting autophagy following peripheral nerve injury. Glia 61, 504-512. doi: 10.1002/glia.22451
Soliman, M. L., Ohm, J. E., and Rosenberger, T. A. (2013). Acetate reduces PGE2 release and modulates phospholipase and cyclooxygenase levels in neuroglia stimulated with lipopolysaccharide. Lipids 48, 651-662. doi: 10.1007/s11745013-3799-x

Soliman, M. L., Puig, K. L., Combs, C. K., and Rosenberger, T. A. (2012). Acetate reduces microglia inflammatory signaling in vitro. J. Neurochem. 123, 555-567. doi: 10.1111/j.1471-4159.2012.07955.x

Song, J., Oh, Y., and Lee, J. E. (2015). miR-Let7A modulates autophagy induction in LPS-activated microglia. Exp. Neurobiol. 24, 117-125. doi: 10.5607/en.2015. 24.2.117

Su, X., Chu, Y., Kordower, J. H., Li, B., Cao, H., Huang, L., et al. (2015). PGClalpha promoter methylation in Parkinson's disease. PLoS One 10:e134087. doi: 10.1371/journal.pone.0134087

Suh, H. S., Choi, S., Khattar, P., Choi, N., and Lee, S. C. (2010). Histone deacetylase inhibitors suppress the expression of inflammatory and innate immune response genes in human microglia and astrocytes. J. Neuroimmune Pharmacol. 5, 521-532. doi: 10.1007/s11481-010-9192-0

Sun, D., Yu, Z., Fang, X., Liu, M., Pu, Y., Shao, Q., et al. (2017). LncRNA GAS5 inhibits microglial M2 polarization and exacerbates demyelination. EMBO Rep. 18, 1801-1816. doi: 10.15252/embr.201643668

Surani, M. A., Durcova-Hills, G., Hajkova, P., Hayashi, K., and Tee, W. W. (2008). Germ line, stem cells, and epigenetic reprogramming. Cold Spring Harb. Symp. Quant. Biol. 73, 9-15. doi: 10.1101/sqb.2008.73.015

Suuronen, T., Huuskonen, J., Pihlaja, R., Kyrylenko, S., and Salminen, A. (2003). Regulation of microglial inflammatory response by histone deacetylase inhibitors. J. Neurochem. 87, 407-416. doi: 10.1046/j.1471-4159.2003. 02004.x

Svahn, A. J., Giacomotto, J., Graeber, M. B., Rinkwitz, S., and Becker, T. S. (2016). miR-124 contributes to the functional maturity of microglia. Dev. Neurobiol. 76, 507-518. doi: 10.1002/dneu.22328

Tahiliani, M., Koh, K. P., Shen, Y., Pastor, W. A., Bandukwala, H., Brudno, Y., et al. (2009). Conversion of 5-methylcytosine to 5-hydroxymethylcytosine in mammalian DNA by MLL partner TET1. Science 324, 930-935. doi: 10.1126/ science. 1170116

Tang, Y., Li, T., Li, J., Yang, J., Liu, H., Zhang, X. J., et al. (2014). Jmjd3 is essential for the epigenetic modulation of microglia phenotypes in the immune pathogenesis of Parkinson's disease. Cell Death Differ. 21, 369-380. doi: 10.1038/cdd.20 13.159

Thounaojam, M. C., Kaushik, D. K., Kundu, K., and Basu, A. (2014). MicroRNA$29 \mathrm{~b}$ modulates Japanese encephalitis virus-induced microglia activation by targeting tumor necrosis factor alpha-induced protein 3. J. Neurochem. 129, 143-154. doi: 10.1111/jnc.12609

Tian, F., Yuan, C., Hu, L., and Shan, S. (2017). MicroRNA-93 inhibits inflammatory responses and cell apoptosis after cerebral ischemia reperfusion by targeting interleukin-1 receptor-associated kinase 4. Exp. Ther. Med. 14, 2903-2910. doi: 10.3892/etm.2017.4874

Vogel Ciernia, A., Careaga, M., LaSalle, J. M., and Ashwood, P. (2018). Microglia from offspring of dams with allergic asthma exhibit epigenomic alterations in genes dysregulated in autism. Glia 66, 505-521. doi: 10.1002/glia.23261

Wang, J., Zhao, H., Fan, Z., Li, G., Ma, Q., Tao, Z., et al. (2017). Long noncoding RNA H19 promotes neuroinflammation in ischemic stroke by driving histone deacetylase 1-dependent M1 microglial polarization. Stroke 48, 2211-2221. doi: 10.1161/STROKEAHA.117.017387

Wang, P., Zhang, Y., Gong, Y., Yang, R., Chen, Z., Hu, W., et al. (2018). Sodium butyrate triggers a functional elongation of microglial process via Akt-small RhoGTPase activation and HDACs inhibition. Neurobiol. Dis. 111, 12-25. doi: 10.1016/j.nbd.2017.12.006

Wen, Y., Yu, Y., and Fu, X. (2017). LncRNA Gm4419 contributes to OGD/R injury of cerebral microglial cells via IkappaB phosphorylation and NF-kappaB activation. Biochem. Biophys. Res. Commun. 487, 923-929. doi: 10.1016/j.bbrc. 2017.05.005

Wendeln, A. C., Degenhardt, K., Kaurani, L., Gertig, M., Ulas, T., Jain, G., et al. (2018). Innate immune memory in the brain shapes neurological disease hallmarks. Nature 556, 332-338. doi: 10.1038/s41586-018-0023-4

Woodbury, M. E., Freilich, R. W., Cheng, C. J., Asai, H., Ikezu, S., Boucher, J. D., et al. (2015). miR-155 is essential for inflammation-induced hippocampal neurogenic dysfunction. J. Neurosci. 35, 9764-9781. doi: 10.1523/JNEUROSCI. 4790- 14.2015 
Xia, L., Zhang, Y., and Dong, T. (2016). Inhibition of microRNA-221 alleviates neuropathic pain through targeting suppressor of cytokine signaling 1. J. Mol. Neurosci. 59, 411-420. doi: 10.1007/s12031-016-0748-1

Xie, X., Peng, L., Zhu, J., Zhou, Y., Li, L., Chen, Y., et al. (2017). miR-145$5 \mathrm{p} /$ Nurr1/TNF-alpha signaling-induced microglia activation regulates neuron injury of acute cerebral ischemic/reperfusion in rats. Front. Mol. Neurosci. 10:383. doi: 10.3389/fnmol.2017.00383

Xing, H., Guo, S., Zhang, Y., Zheng, Z., and Wang, H. (2016). Upregulation of microRNA-206 enhances lipopolysaccharide-induced inflammation and release of amyloid-beta by targeting insulin-like growth factor 1 in microglia. Mol. Med. Rep. 14, 1357-1364. doi: 10.3892/mmr.2016.5369

Yang, Z., Xu, J., Zhu, R., and Liu, L. (2017). Down-regulation of miRNA128 contributes to neuropathic pain following spinal cord injury via activation of P38. Med. Sci. Monit. 23, 405-411. doi: 10.12659/MSM.89 8788

Yang, Z., Zhong, L., Zhong, S., Xian, R., and Yuan, B. (2015). miR-203 protects microglia mediated brain injury by regulating inflammatory responses via feedback to MyD88 in ischemia. Mol. Immunol. 65, 293-301. doi: 10.1016/j. molimm.2015.01.019

Yao, H., Ma, R., Yang, L., Hu, G., Chen, X., Duan, M., et al. (2014). MiR-9 promotes microglial activation by targeting MCPIP1. Nat. Commun. 5:4386. doi: $10.1038 /$ ncomms5386

Yin, H., Song, S., and Pan, X. (2017). Knockdown of miR-155 protects microglia against LPS-induced inflammatory injury via targeting RACK1: a novel research for intracranial infection. J. Inflamm. 14:17. doi: 10.1186/s12950-0170162-7

Yin, M., Chen, Z., Ouyang, Y., Zhang, H., Wan, Z., Wang, H., et al. (2017). Thrombin-induced, TNFR-dependent miR-181c downregulation promotes MLL1 and NF-kappaB target gene expression in human microglia. J. Neuroinflammation 14:132. doi: 10.1186/s12974-017-0887-5

Yuan, B., Shen, H., Lin, L., Su, T., Zhong, L., and Yang, Z. (2015). MicroRNA367 negatively regulates the inflammatory response of microglia by targeting IRAK4 in intracerebral hemorrhage. J. Neuroinflammation 12:206. doi: 10.1186/ s12974-015-0424-3

Zhang, F., Wang, S., Gan, L., Vosler, P. S., Gao, Y., Zigmond, M. J., et al. (2011). Protective effects and mechanisms of sirtuins in the nervous system. Prog. Neurobiol. 95, 373-395. doi: 10.1016/j.pneurobio.2011.09.001

Zhang, X., Wang, Y., Yuan, J., Li, N., Pei, S., Xu, J., et al. (2018). Macrophage/microglial Ezh2 facilitates autoimmune inflammation through inhibition of Socs3. J. Exp. Med. 215, 1365-1382. doi: 10.1084/jem.2017 1417

Zhang, Y., Wei, G., Di, Z., and Zhao, Q. (2014). miR-339-5p inhibits alcohol-induced brain inflammation through regulating NF-kappaB pathway. Biochem. Biophys. Res. Commun. 452, 450-456. doi: 10.1016/j.bbrc.2014. 08.092
Zhang, Z. Y., Zhang, Z., Fauser, U., and Schluesener, H. J. (2007). Global hypomethylation defines a sub-population of reactive microglia/macrophages in experimental traumatic brain injury. Neurosci. Lett. 429, 1-6. doi: 10.1016/j. neulet.2007.09.061

Zhao, H., Wang, J., Gao, L., Wang, R., Liu, X., Gao, Z., et al. (2013). MiRNA424 protects against permanent focal cerebral ischemia injury in mice involving suppressing microglia activation. Stroke 44, 1706-1713. doi: 10.1161/ STROKEAHA.111.000504

Zhao, N., Shen, L., Jiang, H. W., Ma, C., and Huang, Y. G. (2016). Effect of high MiR-146a expression on the inflammatory reaction in BV2 cells. Zhongguo Yi Xue Ke Xue Yuan Xue Bao 38, 27-32. doi: 10.3881/j.issn.1000-503X.2016.01.005

Zhou, H. J., Wang, L. Q., Wang, D. B., Yu, J. B., Zhu, Y., Xu, Q. S., et al. (2018). Long non-coding RNA MALAT1 contributes to inflammatory response of microglia following spinal cord injury via modulating miR-199b/IKKbeta/NFkappaB signaling pathway. Am. J. Physiol. Cell Physiol. 315, C52-C61. doi: 10.1152/ajpcell.00278.2017

Zhou, H. J., Wang, L. Q., Xu, Q. S., Fan, Z. X., Zhu, Y., Jiang, H., et al. (2016). Downregulation of miR-199b promotes the acute spinal cord injury through IKKbeta-NF-kappaB signaling pathway activating microglial cells. Exp. Cell Res. 349, 60-67. doi: 10.1016/j.yexcr.2016.09.020

Zhou, T., Huang, Y. X., Song, J. W., and Ma, Q. M. (2015). Thymosin beta4 inhibits microglia activation through microRNA 146a in neonatal rats following hypoxia injury. Neuroreport 26, 1032-1038. doi: 10.1097/WNR. 0000000000000463

Zhou, Y., Kim, J., Yuan, X., and Braun, T. (2011). Epigenetic modifications of stem cells: a paradigm for the control of cardiac progenitor cells. Circ. Res. 109, 1067-1081. doi: 10.1161/CIRCRESAHA.111.243709

Zhou, Y., Lu, M., Du, R. H., Qiao, C., Jiang, C. Y., Zhang, K. Z., et al. (2016). MicroRNA-7 targets Nod-like receptor protein 3 inflammasome to modulate neuroinflammation in the pathogenesis of Parkinson's disease. Mol. Neurodegener. 11:28. doi: 10.1186/s13024-016-0094-3

Conflict of Interest Statement: The authors declare that the research was conducted in the absence of any commercial or financial relationships that could be construed as a potential conflict of interest.

The reviewer $\mathrm{RH}$ declared a shared affiliation, with no collaboration, with the authors to the handling Editor.

Copyright (c) 2018 Cheray and Joseph. This is an open-access article distributed under the terms of the Creative Commons Attribution License (CC BY). The use, distribution or reproduction in other forums is permitted, provided the original author(s) and the copyright owner(s) are credited and that the original publication in this journal is cited, in accordance with accepted academic practice. No use, distribution or reproduction is permitted which does not comply with these terms. 